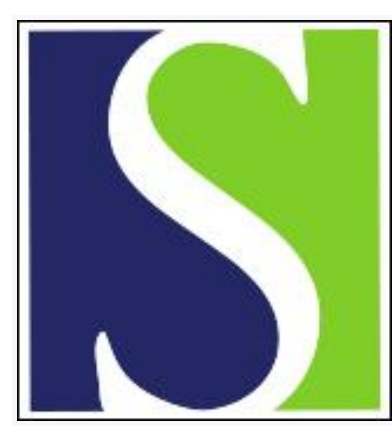

Scand J Work Environ Health 1999;25(1):67-74

https://doi.org/10.5271/sjweh.385

Issue date: Feb 1999

Functional and high-resolution computed tomographic studies of divers' lungs

by Reuter M, Tetzlaff K, Steffens J-C, Glüer C-C, Faeseke KP, Bettinghausen $\mathrm{E}$, Heller $\mathrm{M}$

Key terms: computed tomography; diving; lung function; small airway dysfunction

This article in PubMed: www.ncbi.nlm.nih.gov/pubmed/10204673

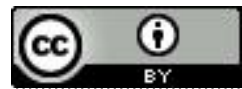




\title{
Functional and high-resolution computed tomographic studies of divers' lungs
}

\author{
by Michael Reuter, MD, ${ }^{1}$ Kay Tetzlaff, MD, ${ }^{2,3}$ Johann-C Steffens, MD, ${ }^{1}$ Claus-C. Glüer, PhD, ${ }^{1}$ Karl Peter \\ Faeseke, MD, ${ }^{4}$ Eyke Bettinghausen, $M D,{ }^{2}$ Martin Heller, $M D^{1}$
}

Reuter M, Tetzlaff K, Steffens J-C, Glüer C-C, Faeseke KP, Bettinghausen E, Heller M. Functional and highresolution computed tomographic studies of divers' lungs. Scand J Work Environ Health 1999;25(1):66-74.

\begin{abstract}
Objectives Several cross-sectional studies have described a decrease in the expiratory flow rates of divers. The objective of this study was to determine whether the combined application of high-resolution computed tomography (HRCT) and lung function testing supports the reported development of small airway obstruction in divers.

Methods Thirty-two navy divers, 27 commercial divers, and 48 referents matched for age and smoking history underwent pulmonary function testing and HRCT of the lungs supplemented by a limited number of expiratory scans. The commercial divers were older and dived longer than the navy divers. Multivariate regression analysis was used to assess the relevant correlations of age, height, pack-years of cigarette smoking, and indices of diving exposure with lung function parameters.

Results The inspiratory vital capacity and forced vital capacity (FVC) were greater, while the FEV\% [(100 $\times$ $\left.\mathrm{FEV}_{1,0}\right) \mathrm{FVCl}$ and maximum expiratory flow (MEF) at $25 \%\left(\mathrm{MEF}_{25}\right)$ of the $\mathrm{FVC}$ were lower for the navy divers than for the referents. The lung volumes and expiratory airflow pattern did not differ between the commercial divers and the corresponding referents. The forced expiratory volume in 1 second $\left(\mathrm{FEV}_{1.0}\right), \mathrm{FEV}, \mathrm{MEF}_{75}$, and $\mathrm{MEF}_{25}$ correlated negatively with the years of diving experience. This association was independent of age, height, and pack-years of cigarette smoking. For the majority of the divers and referents the expiratory HRCT revealed minor lobular air trapping without any difference between the groups. The HRCT did not show relevant morphologic abnormalities of small or large airways.

Conclusions The data confirm that diving may affect pulmonary function. However, there is no radiologic
\end{abstract} evidence for the development of small airway disease in these 2 subgroups of divers.

Key terms computed tomography, diving, lung function, small airway dysfunction.

It is well documented that exposure to a hyperbaric environment can have detrimental effects on various target organs even in the absence of decompression illness. (See reference 1 for a review.) Considerable attention has been focused on the performance of pulmonary function testing to detect functional abnormalities in divers' lungs. A decrease in expiratory flow rates in relation to diving exposure has been a common finding in several crosssectional studies, and the development of small airway disease in divers has been postulated (2-4).
The objective of this investigation was to determine whether the combined application of measurements of lung function and high-resolution computed tomography (HRCT) would provide additional support for the reported development of obstructive airway changes in longstanding occupational diving. The detection of airflow obstruction is of more than academic interest since air trapping of any form has been suggested as possibly increasing the susceptibility of divers to pulmonary barotrauma during ascent $(5,6)$.

1 Department of Diagnostic Radiology, Christian-Albrechts-University, Kiel, Germany.

2 Department of Diving and Hyperbaric Medicine, Naval Medical Institute of the Federal German Navy, Kiel-Kronshagen, Germany.

3 Department of Medicine, Christian-Albrechts-University, Kiel, Germany.

4 Hamburg Port Health Center, Hamburg, Germany.

Reprint requests to: Dr M Reuter, Department of Diagnostic Radiology, Christian-Albrechts-University, Arnold-Heller-Strasse 9, D-24105 Kiel, Germany. 


\section{Subjects and methods}

\section{Subjects}

Between June 1996 and June 1997, 32 navy divers, 27 commercial divers, and a total of 48 referents who had never dived were examined. The divers and referents were matched for age and smoking history. The referents were recruited voluntarily from nondiving navy personnel $(\mathrm{N}=28)$ and commercial employees attending regular health care examinations ( $\mathrm{N}=20$ ). They had not suffered from pulmonary disease and were free of exposure to dusts. The navy divers had a mean age of 39.8 years, while the commercial divers were older, with a mean age of 49.6 years. The subgroups of divers did not differ for body mass index or history of cigarette smoking. The detailed anthropometric data and smoking histories are summarized in table 1 . The commercial divers had a longer diving career than the navy divers, as given by years of diving experience and total diving hours (table 2). All the divers performed compressed air diving with mean maximum depths of 61.5 and $69.5 \mathrm{~m}$ of seawater for navy and commercial divers, respectively. Only 5 commercial divers were experienced in saturation diving, reaching a mean depth of 368 (range $180-600$ ) $\mathrm{m}$, the mean days in saturation being 136 (range 35-191 days.

Participation was voluntary, and a written informed consent was obtained from every subject prior to his participation in the study. The protocol for pulmonary function testing and HRCT of the lungs of the divers and referents had been approved by the regional ethics committee.

\section{Pulmonary function}

All the subjects underwent pulmonary function testing in the morning of the same day as the HRCT study. A computerized pneumotachography system was used (Masterlab, Jaeger, Wuerzburg, Germany). Whole-body plethysmography served for the measurement of total airway resistance (Raw), residual volume (RV), and total lung capacity (TLC). Static and dynamic lung volumes were obtained by spirometry: inspiratory vital capacity (IVC), forced vital capacity (FVC), forced expiratory volume in 1 second $\left(\mathrm{FEV}_{1.0}\right)$, and maximum expiratory flow rates at $75 \%, 50 \%$, and $25 \%$ of the forced vital capacity (FVC) $\left(\mathrm{MEF}_{75}, \mathrm{MEF}_{50}\right.$, and $\mathrm{MEF}_{25}$, respectively) were taken as the best of 3 forced voluntary maneuvers. The transfer factor for carbon monoxide (TLCO) was obtained by the single breath technique, and effective alveolar volume (VA) was derived from helium dilution. TLCO was adjusted for a hemoglobin concentration of $146 \mathrm{~g} / \mathrm{l}$. Calibrations for volume, gas analyzers, and chamber pressure were performed daily in the morning preceding the tests. The values are presented as means of the totals plus standard deviations and as percentages of predicted values according to Quanjer et al (7). The results of the pulmonary function testing of the navy divers were compared with those of the naval referents, and the lung function values of the commercial divers were compared with those of the commercial employee referents.

\section{High-resolution computed tomography}

HRCT of the lungs was performed on all the divers and nondiving navy personnel using a Somatom-Plus-S device (Siemens, Erlangen, Germany). Scans were taken during maximal inspiration from the apex to the base of the lungs with the patient supine. In addition 4 scans were obtained at the end of expiration from the middle and lower lung fields (figure 1). The following parameters were used: 1-second scan time, $275 \mathrm{~mA}$ tube current, 137 $\mathrm{kVp}$ voltage, 1-mm section thickness, $10-\mathrm{mm}$ table feed. The scans were reconstructed using a high spatial frequency reconstruction algorithm and documented at window settings appropriate for lung parenchyma (2000/-450 $\mathrm{HU}$ ). The evaluation was performed by 2 observers (MR, $\mathrm{J}-\mathrm{CS}$ ), in conference, who were blinded as to the history of diving exposure, and a consensus opinion was reached. The HRCT findings of the navy and commercial divers were compared with those of the naval referents.

In accordance with cross-sectional studies of divers' lung function (2-4) and histological morphometric data available on divers' lungs (8), the HRCT analysis was based on the assumption that morphologic changes primarily affect the small airways. Consequently small centrilobular opacities that could reflect abnormalities of the respiratory bronchioli and alveolar spaces or septa surrounding the bronchioli were looked for $(9-10)$. Documentation of large airway abnormalities such as bronchial

Table 1. Anthropometric data and smoking history of the divers and referents.

\begin{tabular}{|c|c|c|c|c|c|c|c|c|}
\hline \multirow[t]{2}{*}{ Study group } & \multicolumn{2}{|c|}{ Age (years) } & \multicolumn{2}{|c|}{ Body mass index $\left(\mathrm{kg} / \mathrm{m}^{2}\right)$} & \multirow[t]{2}{*}{ Nonsmoker (N) } & \multirow[t]{2}{*}{ Smoker $(\mathrm{N})$} & \multicolumn{2}{|c|}{ Pack-years } \\
\hline & Mean & $\mathrm{SD}$ & Mean & SD & & & Mean & $\mathrm{SD}$ \\
\hline \multicolumn{9}{|l|}{ Divers $(\mathrm{N}=59)$} \\
\hline Navy divers $(\mathrm{N}=32)$ & 39.8 & 8.9 & 26.4 & 2.1 & 20 & 12 & 3.8 & 8.6 \\
\hline Commercial divers ( $\mathrm{N}=27$ ) & 49.6 & 9.4 & 27.4 & 3.4 & 18 & 9 & 3.7 & 7.2 \\
\hline \multicolumn{9}{|l|}{ Referents $(\mathrm{N}=48)$} \\
\hline Navy personnel $(\mathrm{N}=28)$ & 37.6 & 8.9 & 26.4 & 4.9 & 15 & 13 & 9.9 & 12.5 \\
\hline Commercial employees $(\mathrm{N}=20)$ & 50.0 & 8.4 & 25.2 & 1.8 & 14 & 6 & 5.2 & 11.4 \\
\hline
\end{tabular}


dilatation or thickening of bronchial walls was included in the protocol. Other signs evaluated in the assessment of small airway disease included centrilobular emphysema and air trapping. This pattern was looked for on all the inspiratory HRCT scans and also on the paired inspiratory-expiratory scans (11). Other abnormalities observed during the assessment of lung parenchyma and not included in the list of signs were categorized according to the recommendations of the nomenclature committee of the Fleischner Society (12).

The aforementioned direct and indirect signs of small airway disease were recorded as present or absent in each of the 6 lobes, the lingula being counted as a separate lobe. In addition, in the case of bronchial dilatation, the number of bronchopulmonary segments involved was recorded. The extent of air trapping was quantified to the nearest $5 \%$ in reference to the cross-sectional area of each expiratory scan and subsequently averaged for the 4 expiratory scans. Finally the distribution of air trapping was recorded as a predominant lobular or diffuse pattern.

\section{Statistics}

All the parameters describing anthropometric data, smoking habits, diving exposure, and pulmonary function were expressed as means and standard deviations. For comparison of the variables between the groups, we selected nonparametric tests based on Wilcoxon rank scores since some parameters were not normally distributed. Categorical comparisons between the HRCT findings and groups were tested for significance using the chi-square test. Multiple regression analysis, performed in a stepwise backward fashion, was used to assess relevant correlations of age, pack-years of cigarette smoking, and indices of diving exposure with the lung function parameters. Correlations between the extent of decreased X-ray attenuation on the expiratory HRCT and the expiratory
Table 2. Details of the diving exposure.

\begin{tabular}{lcccccc}
\hline Study group & \multicolumn{2}{c}{$\begin{array}{c}\text { Years of } \\
\text { employment as } \\
\text { a diver }\end{array}$} & $\begin{array}{c}\text { Total diving } \\
\text { hours }\end{array}$ & \multicolumn{2}{c}{$\begin{array}{c}\text { Maximum } \\
\text { depth of } \\
\text { divea }(\mathrm{m})\end{array}$} \\
\hline Mean & SD & Mean & SD & Mean & SD \\
\hline $\begin{array}{l}\text { Navy divers (N=32) } \\
\begin{array}{l}\text { Commercial } \\
\text { divers }(\mathrm{N}=27)\end{array}\end{array}$ & 16.9 & 5.9 & 1556 & 1040 & 61.5 & 8.0 \\
\hline
\end{tabular}

a In seawater.

${ }^{b}$ The maximun depth of the dives, as given in the table, refers to compressed air diving only; the saturation diving experience of 5 commercial divers was not included. (See the Subjects and Methods section.)

airflow measures were examined using Spearman's rank correlation coefficients. The analysis was performed using JMP( statistical software (version 3.1) from the SAS Institute Inc (Cary, NC, USA).

\section{Results}

\section{Pulmonary function}

The results of the pulmonary function tests are presented in table 3. Although the absolute changes in airway function were small, differences were observed between the navy divers and their referents with respect to the IVC and FVC. Both parameters, indicated as the percentage of predicted values, were larger for the navy divers than for the nondiving navy personnel $(\mathrm{P}<0.01$ and $\mathrm{P}=0.04$, respectively), whereas the measured values did not reveal any difference. The absolute and predicted FEV\% $\left[\left(100 \times \mathrm{FEV}_{1.0}\right) \mathrm{FVC}\right](\mathrm{P}=0.04)$ and $\mathrm{MEF}_{25}(\mathrm{P}<0.01$ and $\mathrm{P}=0.04)$ values were lower for the navy divers than for the referents. In addition we performed a separate analysis for the nonsmoking navy divers and nonsmoking

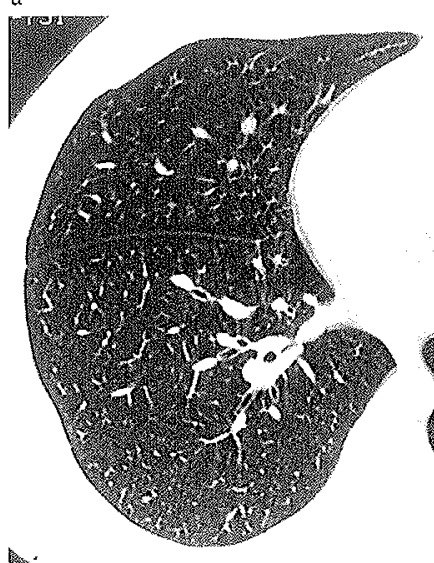

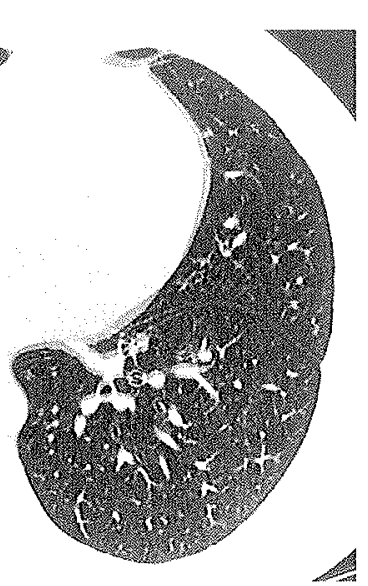

b

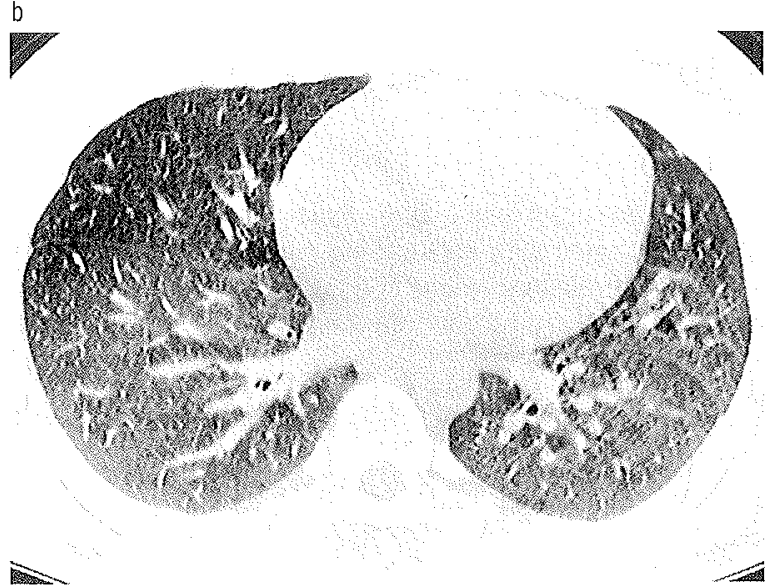

Figure 1. Paired inspiratory-expiratory high-resolution computed-tomographic (HRCT) scans obtained from a 24-year-old nondiving referent showing a homogeneous increase in lung tissue attenuation during end expiration. (a: full inspiration; b: end expiration - both scans performed in the same patient position) 
Table 3. Results of the pulmonary function tests of the divers and referents. (TLC = total lung capacity; pred = predicted; RV = residual volume; $\mathrm{MEF}_{25}=$ maximum expiratory flow at $75 \%, 50 \%$ and $25 \%$ of the forced vital capacity, respectively; TLCO = transfer factor for carbon monoxide;

\begin{tabular}{|c|c|c|c|c|c|c|c|c|c|c|c|c|c|c|c|c|c|c|c|c|c|c|}
\hline \multirow[t]{3}{*}{ Parameter } & \multicolumn{2}{|c|}{$\begin{array}{l}\text { Reff, } \mathrm{kPa}^{*} \\
(\mathrm{~s} / \mathrm{l})\end{array}$} & \multicolumn{4}{|c|}{ TLC } & \multicolumn{4}{|c|}{ RV } & \multicolumn{4}{|c|}{ IVC } & \multicolumn{4}{|c|}{ FVC } & \multicolumn{4}{|c|}{$\mathrm{FEV}_{1.0}$} \\
\hline & \multirow[t]{2}{*}{ Mean } & \multirow[t]{2}{*}{$\mathrm{SD}$} & \multicolumn{2}{|c|}{ Liter } & \multicolumn{2}{|c|}{$\%$ pred } & \multicolumn{2}{|c|}{ Liter } & \multicolumn{2}{|c|}{$\%$ pred } & \multicolumn{2}{|c|}{ Liter } & \multicolumn{2}{|c|}{$\%$ pred } & \multicolumn{2}{|c|}{ Liter } & \multicolumn{2}{|c|}{$\%$ pred } & \multicolumn{2}{|c|}{ Liter } & \multicolumn{2}{|c|}{$\%$ pred } \\
\hline & & & Mean & SD & Mean & $\mathrm{SD}$ & Mean & $\mathrm{SD}$ & Mean & $\mathrm{SD}$ & Mean & SD & Mean & $\mathrm{SD}$ & Mean & $\mathrm{SD}$ & Mean & $\mathrm{SD}$ & Mean & $S D$ & Mean & $\mathrm{SD}$ \\
\hline $\begin{array}{l}\text { Navy } \\
\text { divers (N=32) }\end{array}$ & 0.24 & 0.06 & 7.72 & 0.8 & 107 & 9.5 & 2.2 & 0.5 & 113 & 25.6 & 5.46 & 0.7 & $105^{*}$ & 8.3 & 5.35 & 0.8 & $107^{\star}$ & $* 10.5$ & 4.49 & 0.7 & 109 & 11.0 \\
\hline $\begin{array}{l}\text { Referents } \\
\text { (navy personnel, } \\
N=28 \text { ) }\end{array}$ & 0.25 & 0.06 & 7.68 & 1.2 & 103 & 9.4 & 2.27 & 0.5 & 116 & 23.4 & 5.35 & 0.9 & 99.1 & 8.4 & 5.3 & 0.9 & 102 & 9.4 & 4.54 & 0.7 & 107 & 11.5 \\
\hline $\begin{array}{l}\text { Commercial } \\
\text { divers }(N=27)\end{array}$ & 0.27 & 0.07 & 7.45 & 1.0 & 103 & 11.2 & 2.4 & 0.6 & 108 & 23.5 & 4.96 & 0.9 & 102 & 13.8 & 4.89 & 0.8 & 105 & 14.2 & 4.11 & 0.7 & 110 & 15.0 \\
\hline $\begin{array}{l}\text { Referents (commercial } \\
\text { employees, } N=20 \text { ) }\end{array}$ & 0.26 & 0.08 & 7.5 & 1.0 & 105 & 10.7 & 2.6 & 0.7 & 114 & 27.5 & 4.96 & 0.6 & 103 & 11.2 & 4.78 & 0.7 & 103 & 13.3 & 3.94 & 0.6 & 106 & 15.9 \\
\hline
\end{tabular}

${ }^{*} \mathrm{P}<0.01$ for IIVC (\% predicted) versus referents, ${ }^{* *} \mathrm{P}=0.04$ for FVC (\% predicted) versus referents, ${ }^{* * *} \mathrm{P}=0.04$ for FEV\% versus referents, ${ }^{* * *} \mathrm{P}<0.01$ fo $\mathrm{r}$

naval referents. While the differences in the lung volumes were nonsignificant between the groups, the significances of $\mathrm{FEV} \%$ and $\mathrm{MEF}_{25}$ even increased when the smokers were excluded ( $\mathrm{P}<0.01$ ) (table 4). The lung function parameters did not differ between the commercial divers and their referents.

The multiple regression analysis of age, height, packyears of cigarette smoking, indices of diving exposure, and the lung function parameters of both subgroups of divers is given in table 5. The $\mathrm{FEV}_{1.0}$, the $\mathrm{FEV} \%, \mathrm{MEF}_{75}$ and $\mathrm{MEF}_{25}$ showed a negative correlation with years of diving exposure. Independently of the variables characterizing diving exposure, a negative correlation was found for FVC with age. In addition, RV was positively associated with age, and the diffusion capacity correlated negatively with pack-years of cigarette smoking. There were positive correlations for RV, FVC and $\mathrm{FEV}_{1.0}$ with height.

\section{High-resolution computed tomography}

The HRCT findings from the inspiratory scans of the divers and referents are summarized in table 6 , the

Table 4. Significant lung function findings for nonsmoking navy divers compared with nonsmoking naval referents. (FEV\% $=$ $100 \times$ forced expiratory volume in $1 \mathrm{~s}, F V C=$ forced vital capacity, $\mathrm{MEF}_{25}=$ maximum expiratory flow and $25 \%$ of the forced vital capacity)

\begin{tabular}{|c|c|c|c|c|c|c|}
\hline \multirow[t]{2}{*}{ Parameter } & \multicolumn{2}{|c|}{ FEV\% } & \multicolumn{2}{|c|}{$\mathrm{MEF}_{25}(\mathrm{l} / \mathrm{s})$} & \multicolumn{2}{|c|}{$\mathrm{MEF}_{25}$ (\% predicted) } \\
\hline & Mean & SD & Mean & SD & Mean & SD \\
\hline $\begin{array}{l}\text { Navy divers } \\
\text { (nonsmokers, } \mathrm{N}=20 \text { ) }\end{array}$ & $78.9^{*}$ & 1.48 & $1.71^{*}$ & 0.54 & $77.4^{*}$ & 21.5 \\
\hline $\begin{array}{l}\text { Referents } \\
\text { (nonsmokers, } N=15 \text { ) }\end{array}$ & 5) 86.0 & 1.72 & 2.62 & 0.40 & 108.1 & 26.3 \\
\hline
\end{tabular}

* $P<0.01$ versus referents, as assessed by the Wilcoxon test. presence and extent of air trapping on the scans obtained at the end of expiration are shown in table 7.

Seven $(21.8 \%)$ of the 32 navy divers and $10(37 \%)$ of the 27 commercial divers had a dilated bronchus compared with 7 (25\%) of the 28 referents. In the majority of both the divers and the referents dilated bronchi were confined to 1 bronchopulmonary segment with a diameter no more than 1.5 times that of the accompanying pulmonary artery. Dilated bronchi were detected in 2 bronchopulmonary segments each in 1 navy diver, 3 commercial divers, and 3 referents, respectively. One commercial diver showed dilated bronchi in 3 and 4 segments, respectively, while 1 referent had marked bronchial dilatation in 7 segments.

Emphysema was seen in 7 navy divers (21.8\%), 7 commercial divers (26\%), and 7 referents (25\%). In all the groups emphysematous changes were very discrete, never exceeding $5 \%$ of the respective lobe, the upper lobes being the most frequently involved. Emphysematous lesions were characterized by a centrilobular or paraseptal distribution.

Dependent opacities were found in 8 navy divers (25\%), 5 commercial divers $(18.5 \%)$, and 5 referents They were exclusively found in the lower lobes bilaterally.

Irregular linear opacities and septal thickenings were discrete findings in several divers and referents. Subpleural lines, linear opacities, and consolidations were observed only scarcely.

Disseminated ground glass opacities were detected in both upper lobes of 1 navy diver, interspersed with centrilobular and paraseptal emphysematous changes. The same person had smoked an equivalent of 44 pack-years.

There was no HRCT scan showing small centrilobular opacities or thickened bronchial walls.

On expiratory scans, areas of decreased attenuation of minor extent were a common finding in the 3 study 
$I V C=$ inspiratory vital capacity; $F V C=$ forced vital capacity; $\mathrm{FEV}_{1.0}=$ forced expiratory volume in 1 second; $V C=$ vital capacity; $\mathrm{MEF}_{75}, \mathrm{MEF}_{50}$ and $\mathrm{VA}=$ effective alveolar volume)

\begin{tabular}{|c|c|c|c|c|c|c|c|c|c|c|c|c|c|c|c|c|c|c|c|c|c|}
\hline \multicolumn{2}{|c|}{ FEV\% } & \multicolumn{4}{|c|}{$\mathrm{MEF}_{75}$} & \multicolumn{4}{|c|}{$\mathrm{MEF}_{50}$} & \multicolumn{4}{|c|}{$\mathrm{MEF}_{25}$} & \multicolumn{4}{|c|}{ TLCO SB } & \multicolumn{4}{|c|}{ TLGO VA } \\
\hline \multirow[t]{2}{*}{ Mean } & \multirow[t]{2}{*}{ SD } & \multicolumn{2}{|c|}{ Liter/s } & \multicolumn{2}{|c|}{$\%$ pred } & \multicolumn{2}{|c|}{ Liter/s } & \multicolumn{2}{|c|}{$\%$ pred } & \multicolumn{2}{|l|}{ Liter/s } & \multicolumn{2}{|l|}{$\%$ pred } & \multicolumn{2}{|c|}{$\begin{array}{c}\mathrm{Mmol} \\
(\mathrm{min} \times \mathrm{kPa})\end{array}$} & \multicolumn{2}{|c|}{$\%$ pred } & \multicolumn{2}{|c|}{$\underset{(\mathrm{min} \times \mathrm{kPa} / \mathrm{l})}{\mathrm{Mmol}}$} & \multicolumn{2}{|c|}{$\%$ pred } \\
\hline & & Mean & SD & Mean & $\mathrm{SD}$ & Mean & SD & Mean & SD & Mean & $\mathrm{SD}$ & Mean & SD & Mean & SD & Mean & $\mathrm{SD}$ & Mean & SD & Mean & SD \\
\hline $80.2^{\star \star \star}$ & * 7.6 & 8.84 & 2.2 & 108 & 25.2 & 5.16 & 1.6 & 98.7 & 28.7 & $1.89 * * * *$ & 0.8 & $82.3^{* \star * * \star}$ & 29 & 10.4 & 1.6 & 92.2 & 13.7 & 1.49 & 0.2 & 74.1 & 9.8 \\
\hline 84.0 & 6.3 & 8.56 & 2.1 & 102 & 25.1 & 5.54 & 1.5 & 103 & 29.0 & 2.36 & 0.7 & 96.7 & 30.9 & 10.3 & 1.5 & 88.7 & 9.6 & 1.5 & 0.2 & 74.2 & 11.3 \\
\hline 81.8 & 5.3 & 8.9 & 2.9 & 109 & 24.9 & 4.93 & 1.4 & 95.6 & 32.2 & 1.84 & 0.7 & 91.5 & 37.0 & 10.0 & 1.7 & 94.9 & 13.8 & 1.45 & 0.2 & 76.9 & 10.7 \\
\hline 81.0 & 8.6 & 7.88 & 2.0 & 101 & 25.8 & 4.34 & 1.4 & 89.6 & 30.4 & 1.55 & 0.6 & 77.5 & 31.1 & 9.43 & 1.5 & 89.8 & 11.2 & 1.36 & 0.2 & 72.5 & 7.8 \\
\hline
\end{tabular}

$\mathrm{MEF}_{25}(\mathrm{l} / \mathrm{s})$ versus referents, ${ }^{\star \star * \star \star} \mathrm{P}=0.04$ for $\mathrm{MEF}_{25}$ (\% of predicted) versus referents, as assessed by the Wilcoxon test.

groups (table 7). In all cases, they were arranged in a lobular fashion (figures 2-3). In detail, trapped air of any extent was observed in $40 \%$ of the navy divers, $63 \%$ of the commercial divers, and $54 \%$ of the referents. Hypoattenuating lung parenchyma exceeding $10 \%$ of the averaged cross-sectional area of the 4 expiratory scans was seen in 2 navy divers $(6.2 \%), 6$ commercial divers $(22.2 \%)$, and 3 referents $(10.9 \%)$ only. In 1 navy diver and 1 referent the paired inspiratory scan showed a corresponding area of hypoattenuation, while the remaining inspiratory scans revealed regular lung density. A maximum extent of trapped air, comprising $25 \%$ and $26 \%$ of the cross-sectional area of the expiratory scans, was observed in 2 navy divers.

The preceding HRCT findings and the extent of hypoattenuating parenchyma in the expiratory HRCT scans did not differ significantly between the groups of divers and referents. The extent of air trapping correlated neither with the dynamic lung volumes nor with the indices of diving exposure or pack-years of cigarette smoking.

\section{Discussion}

In underwater diving, the lungs are exposed to a rise in ambient pressure. In this hyperbaric environment, increases in the density of the breathing gas and in the partial pressure of oxygen may contribute to changes in pulmonary function. Breathing dense air results in a rise in airway resistance that reduces airflow and increases inspiratory and expiratory effort (13). Acute effects of exposure to hyperoxia on pulmonary function have been described for experimental saturation dives (14). However, for compressed air diving, exposure to

Table 5. Regression coefficients for age, height, pack-years of cigarette smoking, and indices of diving exposure with significant correlations for the lung function parameters for the divers $(N=59)$. ( $R V=$ residual volume, $F V C=$ forced vital capacity, $F E V_{1.0}=$ forced expiratory volume in 1 second, $\mathrm{VC}=$ vital capacity, $\mathrm{MEF}_{75}=$ maximum expiratory flow at $75 \%$ of the forced vital capacity, $\mathrm{MEF}_{25}=$ maximum expiratory flow at $25 \%$ of the forced vital capacity, $\mathrm{TLCO}=$ transfer factor for carbon monoxide, $\mathrm{SB}=$ single breath, VA $=$ effective alveolar volume)

\begin{tabular}{|c|c|c|c|c|c|c|c|c|}
\hline Parameter & $\begin{array}{c}\text { Age } \\
\text { (years) }\end{array}$ & $\begin{array}{l}\text { Height } \\
(\mathrm{cm})\end{array}$ & Pack-years & $\begin{array}{l}\text { Years of } \\
\text { employment } \\
\text { as a diver }\end{array}$ & $\begin{array}{l}\text { Total diving } \\
\text { hours }\end{array}$ & $\begin{array}{l}\text { Maximum } \\
\text { depth of } \\
\text { dive }(m)\end{array}$ & Intercept & $\mathrm{R} 2$ \\
\hline $\mathrm{RV}(\mathrm{I})$ & $0.03^{*}$ & $0.03^{*}$ & - & - & - & - & -5.23 & 0.32 \\
\hline FVC (I) & $-0.04^{*}$ & $0.05^{*}$ & - & - & - & - & -2.94 & 0.53 \\
\hline $\mathrm{FEV}_{1.0}(\mathrm{l})$ & - & $0.04^{*}$ & - & -0.04 & - & - & -2.20 & 0.50 \\
\hline FEV\% & - & - & - & $-0.22^{* *}$ & - & - & 85.75 & 0.09 \\
\hline $\mathrm{MEF}_{75},(/ / \mathrm{s})$ & - & - & - & $-0.09^{\star \star \star}$ & - & - & 10.66 & 0.10 \\
\hline $\mathrm{MEF}_{75}, \%$ predicted & - & - & - & $-0.74^{* * * *}$ & - & - & 123.0 & 0.07 \\
\hline $\mathrm{MEF}_{25}(\mathrm{l} / \mathrm{s})$ & - & - & - & $-0.06^{*}$ & $0.00004^{*}$ & - & 2.90 & 0.39 \\
\hline $\mathrm{MEF}_{25}$ (\% predicted) & - & - & - & $-1.5^{*}$ & $0.002^{\star \star \star}$ & - & 110 & 0.15 \\
\hline TLCO SB (\% predicted) & - & - & $-0.63^{*}$ & - & - & - & 95.96 & 0.13 \\
\hline TLCO VA, $\mathrm{mmol} / \mathrm{min} / \mathrm{kPa} / \mathrm{l}$ & - & - & $-0.008^{* \star \star}$ & - & - & - & 1.49 & 0.10 \\
\hline TLCO VA (\% predicted) & - & - & $-0.47^{\star}$ & - & - & - & 77.1 & 0.13 \\
\hline
\end{tabular}

${ }^{*} \mathrm{P}<0.01,{ }^{* *} \mathrm{P}=0.02,{ }^{* * *} \mathrm{P}=0.01,{ }^{* \star * *} \mathrm{P}=0.04$ as assessed by multiple regression analysis. 
Table 6. High resolution findings for the divers and referents.

\begin{tabular}{|c|c|c|c|c|c|c|}
\hline \multirow[t]{2}{*}{ Finding } & \multicolumn{2}{|c|}{$\begin{array}{l}\text { Navy divers } \\
(N=32)\end{array}$} & \multicolumn{2}{|c|}{$\begin{array}{c}\text { Commercial } \\
\text { divers } \\
(N=27)\end{array}$} & \multicolumn{2}{|c|}{$\begin{array}{c}\text { Referents } \\
\text { (navy } \\
\text { personnel, } \\
N=28 \text { ) }\end{array}$} \\
\hline & $N$ & $\%$ & N & $\%$ & N & $\%$ \\
\hline Bronchial dilatation & 7 & 21.8 & 10 & 37 & 7 & 25 \\
\hline Emphysema & 7 & 21.8 & 7 & 26 & 7 & 25 \\
\hline Dependent opacity & 8 & 25.0 & 5 & 18.5 & 5 & 17.8 \\
\hline Subpleural line & 1 & 3.1 & 1 & 3.7 & - & \\
\hline Irregular linear opacity & 6 & 18.7 & 6 & 22.2 & 9 & 32.1 \\
\hline Linear opacity & 1 & 3.1 & - & & 1 & 3.6 \\
\hline Septal thickening & 5 & 15.6 & - & & 3 & 10.7 \\
\hline Ground-glass opacity & 1 & 3.1 & - & & - & \\
\hline Consolidation & 1 & 3.1 & 1 & 3.7 & - & \\
\hline Decreased attenuation & 1 & 3.1 & - & & 1 & 3.6 \\
\hline
\end{tabular}

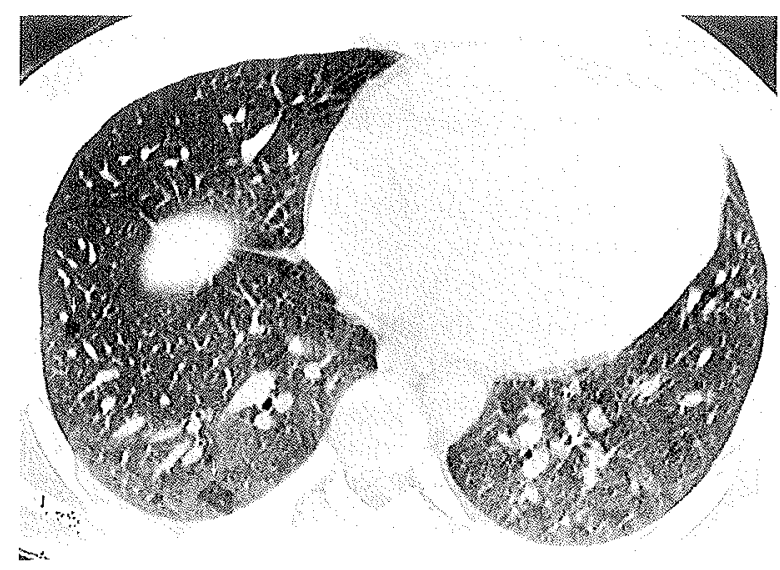

Figure 2. Forced air trapping confined to 2 nonadjacent secondayr pulmonary lobules (arrows) observed in a 26-year-old navy diver during expiration.

hyperoxia seems to be negligible, and the reductions in diffusion capacity found after open sea air dives (15) and simulated air dives $(16,17)$ have been attributed to pulmonary microembolization. Clinically undetectable venous gas microemboli are generated during asymptomatic decompression from depth and are filtered in the pulmonary circulation.

Several cross-sectional studies have described chronic changes in divers' lung function. Unusually large lung volumes have been documented for divers $(3,4,18)$. Training of the respiratory musculature has been attributed to this enlargement of the lungs. Selection has been found to influence this finding (19). However, morphometric measurements of alveoli in fatally injured professional divers have shown that increases in vital capacity are closely related to increases in alveolar size (8). Contrary to increases in static lung volumes reductions in dynamic lung volumes have been observed in both saturation (20) and compressed air divers (2-4). The
Table 7. Air trapping in the divers and referents.

\begin{tabular}{|c|c|c|c|c|c|c|}
\hline \multirow[t]{2}{*}{ Air trappinga } & \multicolumn{2}{|c|}{$\begin{array}{l}\text { Navy divers } \\
(\mathrm{N}=32)\end{array}$} & \multicolumn{2}{|c|}{$\begin{array}{c}\text { Commercial } \\
\text { divers } \\
(N=27)\end{array}$} & \multicolumn{2}{|c|}{$\begin{array}{c}\text { Referent } \\
\text { subjects } \\
\text { (navy } \\
\text { personnel } \\
\quad N=28 \text { ) }\end{array}$} \\
\hline & $N$ & $\%$ & $N$ & $\%$ & $\mathrm{~N}$ & $\%$ \\
\hline 0 & 19 & 59.4 & 10 & 37.1 & 13 & 46.1 \\
\hline$>0<5$ & 7 & 21.9 & 8 & 29.6 & 10 & 35.8 \\
\hline $5<10$ & 4 & 12.5 & 3 & 11.1 & 2 & 7.2 \\
\hline $10<15$ & - & & 3 & 11.1 & 2 & 7.2 \\
\hline $15<20$ & - & & 3 & 11.1 & - & \\
\hline $20<25$ & - & & - & & 1 & 3.7 \\
\hline $25<30$ & 2 & 6.2 & - & & - & \\
\hline
\end{tabular}

a Air trapping indicated as averaged percentage of cross-sectional area of the 4 expiratory scans obtained for the middle and lower lung fields.

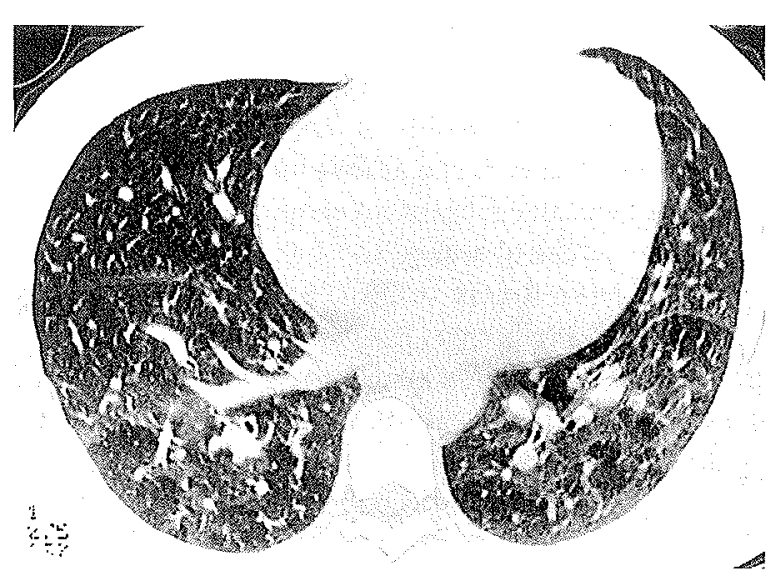

Figure 3. Expiratory high-resolution computed tomography (HRCT) scans obtained from a 42-year-old commercial diver demonstrating multifocal air trapping located in several secondary pulmonary lobules.

decrease in expiratory flow rates at low lung volumes may indicate a disorder of the small airways. It has been proposed that the distension of alveoli in hyperinflated lungs may cause narrowing of small airways with diameters not increased in proportion (8). Other groups have speculated upon bronchiolar hypertrophy secondary to chronic inflammation $(2,3)$ or loss of pulmonary elastic tissue as a cause of obstructive changes (3).

We performed both pulmonary function testing and HRCT of the lungs for 32 navy divers and 27 commercial divers practicing compressed air diving. The navy and commercial divers differed with respect to age and indices of diving exposure, the commercial divers being, on an average, 10 years older and diving longer. For comparison, specific referents matched for age and smoking history underwent the same procedure. The lung function test results of the navy divers were consistent with those reported in the literature $(2-4,18,20)$, that is, large lung volumes and reduced expiratory airflow at low lung 
volumes. Compared with the results of the referents, these changes in airway function were small but of statistical significance. The extent of the functional abnormalities was less marked than has been reported in other studies (20). This finding may reflect the small number of saturation divers involved in this study. When subtle changes in lung function are in question, smokers can ruin the scenario, as smoking is by far the most single dangerous factor to lung tissue. Therefore, we performed a separate analysis for the nonsmoking navy divers and nonsmoking naval referents. In these subgroups, the differences in the parameters monitoring expiratory airflow even increased after the smokers were excluded.

The values for the diffusing capacity of all the groups of divers and referents were somewhat lower than those given by Thorsen et al (20). As exposures to dust could not be ascertained and as the fraction of smokers was not increased compared with the results of the cross-sectional study of Thorsen et al (20), we are not able to give a conclusive explanation for this finding.

The lung volumes and expiratory airflow pattern did not differ between the commercial divers and the referents. Data on divers of similar age are not available for comparison since published cross-sectional studies exclusively refer to an age-bracket of $28-33$ years $(2-4,18$, $20,21)$. The differences in the lung volumes between the 2 subgroups of divers compared with their corresponding referents may be attributed to the influence of age, which, next to height, is the most important factor in the determination of spirometric values. This view is supported by an investigation of Crosbie et al, who studied 404 commercial divers. They described an increase in FVC with years of diving to about 30 years of age, whereas thereafter the FVC declined despite permanent underwater work (3). Similar findings have been reported by Watt (21) in a longitudinal study covering an interval of 3 to 9 years. The reported positive correlation between lung volumes and maximum diving depth $(2,18)$ was confirmed by this study only if the statistical analysis included those few saturation divers who went the deepest.

The lack of a significant difference in $\mathrm{MEF}_{25}$ between the commercial divers and their referents was surprising. In view of the considerably stronger diving exposure of the commercial divers as compared with the navy divers and the equivalent smoking habits of both subgroups of divers, one would have expected a reduction in expiratory airflow. The reason for this finding could not be ascertained. A possible explanation might be selection by the "healthy worker effect" among commercial divers. The influence of diving on pulmonary function is reflected by a negative correlation of indices of expiratory airflow - especially $\mathrm{MEF}_{25}$ - with years of diving experience independent of the influence of age, height, and cigarette smoking. This finding confirms published data (2).
Expiratory flow rates at low lung volumes are generally appreciated as a relatively sensitive measure of small airway dysfunction (22). In order to elucidate the aforementioned findings further, we performed HRCT at both full inspiration and at the end of expiration, in addition to assessing pulmonary function testing, as already undertaken in several cross-sectional studies (2-4, 18, 20 , 21). Recently, expiratory HRCT has proved to be sensitive in showing small airway obstruction in patients with various conditions (23-26). A correlation between the extent of decreased X-ray attenuation on expiratory CT scans and physiological measures of airway obstruction was observed in patients with bronchiectasis (24) and advanced obliterative bronchiolitis (25). HRCT supplemented by expiratory scans may determine the site of airway obstruction at a lobular level (27), and thus it combines anatomic and physiological information. However, when this technique is applied, it should be recognized that occasional subsegmental air trapping has been described for healthy subjects $(26,28)$. It was concluded that the extent of air trapping rather than simply its presence is of importance in the evaluation of persons with suspected small airway obstruction (11). As only a small number of healthy people has been examined thus far, the true range of incidental expiratory HRCT findings and the influence of age on these findings is not completely known. Therefore, we applied expiratory HRCT in our investigation of divers and nondiving navy personnel.

For the divers and nondiving referents the expiratory scans revealed focal areas of hypoattenuating lung parenchyma of similar extent. In all the cases air trapping was characterized by a subsegmental distribution, and in the majority of the cases it affected less than $10 \%$ of the cross-sectional area. The expiratory HRCT findings for the divers were indistinguishable from those of the referents, and they corresponded well to published data collected for a limited number of healthy people $(26,28)$. A morphologic evaluation of lung parenchyma revealed neither relevant abnormalities of small or large airways nor significant emphysema. There were equal numbers of persons with mild bronchial dilatation in both groups of divers and referents when the bronchus:vessel ratio was applied as a criterion. An even higher prevalence of dilated bronchi has been reported for healthy subjects (29). Scattered ground glass opacities interspersed with mild emphysematous changes observed in a heavy smoking navy diver are probably unrelated to diving. According to the pathologic HRCT correlations, they may result from peripheral inflammation induced by cigarette smoking (30).

We performed an epidemiologic investigation among 2 subgroups of occupational divers and an appropriate population for comparison based on pulmonary function testing and HRCT of the lungs. The differences in 
airflow pattern between the navy divers and referents were consistent with published data and might be related to long-term effects on pulmonary function in divers. However, it is of interest to note that between the commercial divers and referents similar differences in airflow pattern were not found in spite of a considerably longer diving career. Our data obtained by HRCT did not show any evidence of abnormal air trapping in those who have been diving either for navy or commercial purposes. The situation may be different for saturation divers, who were not included in this study and whose functional abnormalities are reported to be more severe than those of air divers (20). In conclusion, neither the pulmonary function testing performed on a well-experienced middleaged group of commercial divers nor radiologic findings obtained in the study group as a whole support the view of the development of small airway disease in divers. To determine the long-term significance of reduced airflow in the subgroup of navy divers a longitudinal study will be undertaken.

\section{References}

1. Elliott DH, Moon RE. Long-term health effects of diving. In: Bennet PB, Elliott DH, editors. The physiology and medicine of diving. 4th ed. London: Saunders, 1993:585-604.

2. Davey IS, Cotes JE, Reed JW. Relationship of ventilatory capacity to hyperbaric exposure in divers. J Appl Physiol 1984;56:1655-8.

3. Crosbie WA, Reed JW, Clarke MC. Functional characteristics of the large lungs found in commercial divers. J Appl Physiol 1979;46:639-45.

4. Clifford GM, Smith DJ, Searing CSM. A comparison of lung volumes between divers and submariners in the Royal Navy. J R Nav Med Serv 1984;70:143-8.

5. Reuter M, Tetzlaff K, Warninghoff V, Steffens JC, Bettinghausen E, Heller M. Computed tomography of the chest in diving-related pulmonary barotrauma. $\mathrm{Br} \mathrm{J}$ Radiol 1997;70:440-5.

6. Tetzlaff K, Reuter M, Leplow B, Heller M, Bettinghausen E. Risk factors for pulmonary barotrauma in divers. Chest 1997;112:654-9.

7. Quanjer PH, Tammeling GI, Cotes JE, Pedersen OF, Peslin R, Yernault JC. Lung volumes and forced ventilatory flows: report working party standardization of lung function tests. Eur Respir J 1993;6 suppl 16:5-40.

8. Calder IM, Sweetnham K, Chan KK, Williams MMR. Relation of alveolar size to forced vital capacity in professional divers. Br J Ind Med 1987;44:467-9.

9. Gruden JF, Webb WR, Warnock M. Centrilobular opacities in the lung on high resolution CT: diagnostic considerations and pathologic correlation. AJR 1994;162:569-74.

10. Teel GS, Engeler CE, Tashijian JH, duCret RP. Imaging of small airways disease. RadioGraphics 1996;16:27-41.

11. Stern EJ, Frank MS. Small-airway diseases of the lungs: findings at expiratory CT. AJR 1994;163:37-41.
12. Austin JHM, Müller NL, Friedman PJ, Hansell DM, Naidich DP, Remy-Jardin M, et al. Glossary of terms for CT of the lungs: recommendations of the nomenclature committee of the Fleischner Society. Radiology 1996;200:327-31.

13 Van Liew HD. Mechanical and physical factors in lung function during work in dense environments. Undersea Biomed Res 1983;10:255-64.

14. Thorsen E, Segadal K, Reed JW, Elliott C, Gulsvik A, Hjelle JO. Contribution of hyperoxia to reduced pulmonary function after deep saturation dives. J Appl Physiol 1993;75:657-62.

15 Skogstad M, Thorsen E, Haldorsen T, Melbostad E, Tynes T, Westrum B. Diversï pulmonary function after open-sea bounce dives to 10 and 50 meters. Undersea and Hyperbaric Med 1996;23:71-5.

16. Thorsen E, Risberg J, Segadal K, Hope A. Effects of venous gas microemboli on pulmonary gas transfer function. Undersea Hyperbaric Med 1995;22:347-53.

17. Dujic Z, Eterovic D, Denoble P, Krstacic G, Tocilj J, Gosovic $S$. Effect of a single air dive on pulmonary diffusing capacity in professional divers. J Appl Physiol 1993;74:55-61.

18. Crosbie WA, Clarke MB. Physical characteristics and ventilatory function of 404 commercial divers working in the North Sea. Br J Ind Med 1977;34:19-25.

19 Bouhuys A, Beck GJ. Large lungs in divers? J Appl Physiol $1979 ;: 1136-7$.

20. Thorsen E, Segadal K, Kambestad B, Gulsvik A. Diversï lung function: small airways disease? Br J Ind Med 1990;47:519_23.

21. Watt SJ. Effect of commercial diving on ventilatory function. Br J Ind Med 1985;42:59—62.

22 McFadden ER, Linden RA. A reduction in maximal endexpiratory flow rate: a spirographic manifestation of small airway disease. Am J Med 1972;52:725-37.

23 Stern EJ, Webb WR, Gamsu G. Dynamic quantitative computed tomography: a predictor of pulmonary function in obstructive lung diseases. Invest Radiol 1994;29:564—9.

24. Hansell DM, Wells AU, Rubens MB. Bronchiectasis: functional significance of areas of decreased attenuation at expiratory CT. Radiology 1994;193:369—74.

25. Hansell DM, Rubens MB, Padley SPG, Wells AU. Obliterative bronchiolitis: individual CT signs of small airways disease and functional correlation. Radiology 1997;203:721-6.

26 Park CS, Müller NL, Worthy SA, Kim JS, Awadh N, Fitzgerald $M$. Airway obstruction in asthmatic and healthy individuals: inspiratory and expiratory thin-section CT findings. Radiology 1997;203:361-7.

27. Müller NL, Thurlbeck WM. Thin-section CT, emphysema, air trapping, and airway obstruction. Radiology 1996;199:621-2.

28. Webb WR, Stern EJ, Kanth N, Gamsu G. Dynamic pulmonary CT: findings in healthy adult men. Radiology 1993;186:117-24.

29. Lynch DA, Newell JD, Tschomper BA, Cink TM, Newman LS, Bethel R. Uncomplicated asthma in adults: comparison of CT appearance of the lungs in asthmatic and healthy subjects. Radiology 1993;188:829-33.

30. Remy-Jardin M, Remy J, Gosselin B, Becette V, Edme L. Lung parenchymal changes secondary to cigarette smoking: pathologic-CT correlations. Radiology 1993;186:643-51.

Received for publication: 24 March 1998 